\title{
Parents' perception about child's height and psychopathology in community children with relatively short stature
}

Jun-Won Hwang, MD', Ji-Young Seo, MD ${ }^{2}$

'Department of Psychiatry, Kangwon National University School of Medicine, Chuncheon, 'Department of Pediatrics, Eulji General Hospital, Eulji University College of Medicine, Seoul, Korea
Received: 13 May, 2015

Revised: 9 June, 2015

Accepted: 13 June, 2015

\author{
Address for correspondence: \\ Ji-Young Seo, MD \\ Department of Pediatrics, \\ Eulji General Hospital, Eulji \\ University College of Medicine, \\ 68 Hangeulbiseok-ro, Nowon-gu, \\ Seoul 139-711, Korea \\ Tel: +82-2-970-8226 \\ Fax: +82-2-976-5441 \\ E-mail: pedseo@eulji.ac.kr
}

Purpose: This study investigated the relationship between height and psychopathology in community children with relatively short stature according to the parents' reports. Also, the matter of parental concern about child's height was explored.

Methods: The child behavior checklist $(\mathrm{CBCL})$, the Brief Encounter Psychosocial Instrument (BEPSI), and the child-health questionnaire-parent form 50 (CHQ-PF50) were administered to 423 parents (from elementary and middle school children's) in Gangnam, South Korea. Subjects were divided into three groups; (1) relatively short $(n=30),(2)$ average stature $(n=131)$, (3) relatively tall $(n=153) . C B C L, B E P S I$, and CHQPF50 scores were compared among three groups.

Results: There were no significant differences in psychosocial burden associated with relatively short stature measured by Korean version of the BEPSI and Korean version of the $C B C L$ scores among three groups. But general health perception score of relatively short was significantly lower than that of nonshort on the CHQPF50. Also, they were more used complementary medicines, milk and growth hormone compared to the nonshort. The parents' expected height of their children was $180.6 \pm 3.5 \mathrm{~cm}$ for boys and $166.7 \pm 3.5 \mathrm{~cm}$ for girls. This is respectively 90 percentile and 75-90 percentile for the Korean standard adult height.

Conclusion: Our study shows that in Korea, Parents tended to regard relatively short children as having health problems. Also, the parental expectation for their child's attainable height is unrealistically tall, mostly due to lack of correct medical information.

Keywords: Psychopathology, Short stature, Child behavior

\section{Introduction}

Short stature is statistically defined as a height standard deviation score $<-2$ or $<3$ rd percentile for their age. However, children even who have average heights are visiting pediatric specialty clinic setting to seek evaluation for short stature. Previous studies reported that only $18 \%-30 \%$ children who visited hospital for concerning about their height were short stature ${ }^{1-3)}$.

Nowadays in Korea, many parents and children want to have tall stature and psychosocial stress associated with short stature is increased. Especially, major cause of visit was parents' concerning about their children's height ${ }^{2)}$. Until now, although such psychosocial influences of short stature have been reported, there have been inconsistent reports regarding the short stature that could cause adverse psychosocial consequences. Some studies reported that short children have higher rates of behavioral difficulties and lower social competency, compared with children of normal stature ${ }^{4-6)}$. However, more recent studies reported that short children have normal psychosocial adjustment and the social, emotional, behavioral outcomes did not 
differ from their nonshort peers ${ }^{7-10}$. However, interpretation of those studies was limited by several factors. Some studies included children with growth hormone (GH) deficiency or other syndromes, which made it unclear whether the underlying pathologic condition or short stature is responsible for the difficulties in psychosocial adjustment ${ }^{10-12}$. There are few studies regarding parents' anxiety and relatively normal short children concerning their height.

Based on previous reports on relevant topics, we hypothesized that relatively short (R-short) children even if who are not short in medically would have more psychosocial problems (hypothesis 1) and the parents of them will have more stress about child's height (hypothesis 2). As auxiliary hypotheses, we expected that there would be correlations between the score of quality of life (QoL) and height (hypothesis 3). Moreover, in R-short children, parents may have more tendency to use complementary therapy.

\section{Materials and methods}

\section{Participants}

The study included 423 parents in the elementary and middle school from the one city of Korea. In order to recruit more representative sample, we selected randomly and evenly participants from all of the school in Gangnam, South Korea. Parents who have children with a history of chronic illness which affects their height are excluded. This study was conducted as a part of Stress Camp supervised by Seoul Gangnam District Office of Education. Relevant school committees reviewed and approved the study protocol. After a full explanation of the study was given to all parents, written informed consent was obtained and assent was obtained from the participants prior to their enrollment in the study. Participants were given individual questionnaire packets requiring about 30 minutes to complete. The child behavior checklist (CBCL), the brief encounter psychosocial instrument (BEPSI) and the child-health questionnaire-parent form 50 (CHQ-PF50) were administered to children's parents who voluntarily participated in the current study. After excluding 81 subjects who did not fill up more than $10 \%$ of total items or whose auxological data were not available, information on the remaining 342 children was used for the statistical analysis (response rate, 80.8\%). There were no significant differences in demographic variables between excluded and included subjects.

In order to explore relationships among degree of stature, behavior pattern, stress burden and QoL, subjects were divided into three groups based on their height percentile. Using the Korean standard height percentile ${ }^{13)}$, we defined children with a height from the 25th percentile to 75 th percentile for their age and gender as average stature, above 75 th percentile as relatively tall (R-tall) and below 25th percentile as R-short. Finally, subjects were divided into 30 R-short, 131 average stature and $153 \mathrm{R}$-tall children. Unfortunately, the number of R-short is too small. It can be inferred that we used 2007 version of Korean standard growth chart.

\section{Study measures}

Main outcome measures included parents' Report Form CBCL, CHQ-PF50, and Korean version of the BEPSI (K-BEPSI) and questionnaire about parents perceptions and interest of children's heights.

1) Children behavior checklist

The CBCL is a 138 -item questionnaire completed by the parents ${ }^{14)}$. It provides standardized information regarding social competence and behavioral problems of children 4-16 years old. We applied the second part of Korean version of the CBCL (K-CBCL), the total problem behavior scale, includes 119 items addressing emotional and behavioral problems. The K-CBCL has been demonstrated to be valid and reliable ${ }^{15}$.

2) Child-health questionnaire-parent form 50

This is a generic health status measure designed to record physical and psychosocial well-being of children $\geq 5$ years of age ${ }^{16)}$. It assesses the child's physical and mental health and the mother's and father's perceptions of the extent to which problems in these areas interfere with peer and school activities, family activities, and the lives of mothers/fathers. In accordance with the recommendations established in the child health questionnaire manual, prior to the analysis of results, we transformed the raw score of each scale to $0-100$ scales, with higher scores indicating a better QoL. Two summary scores (physical and psychosocial) were calculated. A physical or psychosocial summary score of 50 represents the mean for the general United States population. Ten points above/ below reflects one standard deviation (SD) difference in either direction.

3) Brief encounter psychosocial instrument ${ }^{17)}$.

The modified BEPSI was utilized in this study. It consists of five items and a score five point Likert scale; a sum of five items score was divided by five. A subject with a higher score experiences more stress. It is useful method to assess of stress rapidly in busy office setting.

\section{Data analysis}

The total score and subscales of the CBCL, BEPSI, and CHQ-PF50 were compared among three groups using oneway analysis of variance (ANOVA) and post hoc Scheffe test. Differences in sociodemographic variables among three groups were tested using a one-way ANOVA for continuous variables and a chi-square test for categorical variables. Only variables with group differences were entered in the multiple regression model, controlling for age and gender. A $P$-value less than 0.05 was used for the significance criteria. All statistical analyses were two tailed and conducted using the SPSS ver. 11.0 (SPSS Inc., Chicago, IL, USA). 


\section{Results}

\section{Psychopathology}

CBCL and BEPSI were performed to evaluate psychopathology and behavior problems associated with short stature but there were no significant differences among three groups (Data not shown).

\section{Characteristics of the high stress group}

Out of 423 parents, $342 \mathrm{~K}$-BEPSI respondents (response rate $80.8 \%)$ were classified as a degree of stress. The respondents of $1.5 \mathrm{SD}$ or higher were defined as a high stress group $(\mathrm{n}=23)$ who were compared to those of the control group $(n=319)$. The modified BEPSI consists of five items and a score five point Likert scale; a sum of five items score was divided by five. A subject with a higher score experiences more stress.

There were no significant differences in the parents' demographical information (e.g., marital status, financial status, education level, religion, etc.) between the two groups. The age and height of those in the high stress group was significantly higher $(P=0.016$ and $P=0.021$ ), but there were no significant differences in sexual development. Children did not exhibit any significant differences in weight and body mass index (BMI), but BMI of the high stress group tended to be relatively lower (Table 1).

\section{Analyzing mental health and QoL of the high stress group}

The main behavioral problems of the high stress group evaluated with the K-CBCL showed significantly higher score at all indicators except social problems (Table 2). Although, T scores (Raw scores can be converted to age-standardized scores; mean \pm SD, 50 \pm 10 ) less than 67 are considered in the normal range, higher stress group can be associated with problematic behavior than control.

The CHQ-PF50 was used to evaluate 15 indicators on the value of life in the high stress group. Out of these, scores of the high stress group on 13 indicators, namely, physical functions, emotional/behavioral role restrictions, physical role restrictions, physical pain/discomfort, behaviors, general behaviors, mental health, self-efficacy, general health awareness, health changes, time loss of parents, family activities, and family cohesiveness were significantly lower than those of the other groups, except for the indicators for general health conditions perceived by parents and emotional influences on the parents (Table 3).

\section{Quality of life}

To evaluate QoL in children and adolescence according to the stature groups, we compared the score of CHQ-PF50 among three groups. The score of general health perceptions of R-short was significantly lower than that of R-tall (ANOVA with post hoc Scheffe test: $F=4.774, P=0.009)$ and otherwise indices were no

Table 1. Baseline demographic and clinical characteristics in high stress group and control groups

\begin{tabular}{lcccc}
\hline Variable & High stress group $(\mathrm{n}=23)$ & Control group $(\mathrm{n}=319)$ & Chi-square or t & P-value \\
\hline Age $(\mathrm{yr})$ & $13.8 \pm 1.7$ & $12.3 \pm 2.8$ & -2.421 & 0.016 \\
Sex & & & & 4.537 \\
$\quad$ Female:male & $9: 14$ & $190: 129$ & -2.328 & 0.103 \\
Height $(\mathrm{cm})$ & $162.6 \pm 7.9$ & $154.1 \pm 16.2$ & -0.576 & 0.021 \\
Body weight $(\mathrm{kg})$ & $48.7 \pm 13.8$ & $46.8 \pm 14.9$ & 1.828 & 0.565 \\
Body mass index $\left(\mathrm{kg} / \mathrm{m}^{2}\right)$ & $17.6 \pm 6.1$ & $19.1 \pm 3.6$ & 0.069 \\
\hline
\end{tabular}

Values are presented as mean \pm standard deviation.

Table 2. Differences in subscales of $C B C L$ between high stress group and control group

\begin{tabular}{lccrr}
\hline \multirow{2}{*}{ K-CBCL } & \multicolumn{2}{c}{ K-CBCLT score } & \multicolumn{1}{c}{ T } & P-value \\
\cline { 2 - 4 } Withdrawn & High stress group & Control group & -2.751 & 0.006 \\
Somatic complaints & $51.9 \pm 12.0$ & $45.6 \pm 11.3$ & -4.587 & $<0.001$ \\
Anxious/depressed & $53.0 \pm 9.5$ & $46.4 \pm 6.9$ & -3.958 & $<0.001$ \\
Social problems & $52.0 \pm 8.9$ & $45.3 \pm 8.3$ & -1.153 & 0.121 \\
Thought problems & $49.4 \pm 10.9$ & $46.7 \pm 8.2$ & -4.282 & $<0.001$ \\
Attention problems & $53.2 \pm 7.6$ & $48.2 \pm 5.6$ & -3.560 & $<0.001$ \\
Delinquent behavior & $51.9 \pm 8.0$ & $45.7 \pm 8.6$ & -3.283 & 0.001 \\
Aggressive behavior & $49.6 \pm 8.8$ & $45.4 \pm 6.1$ & -4.878 & $<0.001$ \\
Internalizing problems & $52.6 \pm 9.3$ & $44.4 \pm 8.2$ & -4.304 & $<0.001$ \\
Externalizing problems & $52.0 \pm 9.7$ & $44.4 \pm 8.6$ & -4.962 & $<0.001$ \\
Total problems & $52.1 \pm 8.8$ & $43.9 \pm 8.1$ & -4.854 & $<0.001$ \\
\hline
\end{tabular}

Values are presented as mean \pm standard deviation.

$\mathrm{CBCL}$, child behavior checklist; $\mathrm{K}-\mathrm{CBCL}$, Korean $\mathrm{CBCL}$. 
significantly differences (Table 4).

\section{Parental perception and help-seeking behaviors}

We gave six individual questionnaires about parental perception and help-seeking behavior to the parents. Parents' expected height according to the stature groups were $178.4 \mathrm{~cm}, 179.9$ $\mathrm{cm}, 181.5 \mathrm{~cm}$ for boys and $163.0 \mathrm{~cm}, 166.2 \mathrm{~cm}, 168.0 \mathrm{~cm}$ for girls respectively. Parents of R-tall expected rather taller height than other 2 groups (ANOVA with post hoc Scheffe test: in boys, $F=10.729, P<0.001$; in girls, $F=22.149, P<0.001$ ) (Table 5).

In addition, parents of R-short tried in more complementary way with herbal medicines, GH, and even milk to increase the height of their children compared to other 2 groups (chi-square

Table 3. Differences in subscales of CHQ-PF-50 between high stress group and control group

\begin{tabular}{|c|c|c|c|c|}
\hline CHQ-PF-50 & High stress group & Control group & $\mathrm{T}$ & $P$-value \\
\hline Global general health & $62.3 \pm 21.8$ & $68.9 \pm 19.6$ & 1.661 & 0.097 \\
\hline Physical function & $77.5 \pm 30.3$ & $96.6 \pm 9.6$ & 7.535 & $<0.001$ \\
\hline \multicolumn{5}{|l|}{ Role/social limitations } \\
\hline Emotional/behavioral & $76.5 \pm 28.5$ & $93.4 \pm 14.5$ & 5.278 & $<0.001$ \\
\hline Physical & $86.0 \pm 24.4$ & $95.4 \pm 13.0$ & 3.245 & 0.001 \\
\hline Bodily pain/discomfort & $70.0 \pm 27.9$ & $85.5 \pm 17.9$ & 4.098 & $<0.001$ \\
\hline Behavior & $68.5 \pm 17.1$ & $84.1 \pm 12.6$ & 5.899 & $<0.001$ \\
\hline Global behavior & $59.2 \pm 25.4$ & $69.9 \pm 21.9$ & 2.360 & 0.019 \\
\hline Mental health & $71.0 \pm 17.3$ & $83.2 \pm 11.8$ & 4.853 & $<0.001$ \\
\hline Self-esteem & $66.2 \pm 17.1$ & $77.5 \pm 17.7$ & 3.107 & 0.002 \\
\hline General health perceptions & $54.7 \pm 13.8$ & $60.6 \pm 11.9$ & 2.366 & 0.019 \\
\hline Emotional impact on parent & $48.7 \pm 23.8$ & $54.1 \pm 24.5$ & 1.076 & 0.282 \\
\hline Time impact on parent & $58.1 \pm 30.5$ & $77.0 \pm 24.1$ & 3.794 & $<0.001$ \\
\hline Family activities & $63.2 \pm 18.7$ & $78.7 \pm 16.9$ & 4.339 & $<0.001$ \\
\hline Family cohesion & $53.4 \pm 18.2$ & $66.9 \pm 22.0$ & 2.997 & 0.003 \\
\hline
\end{tabular}

Values are presented as mean \pm standard deviation.

CHQ-PF50, child-health questionnaire-parent form 50.

Table 4. Comparisons of CHQ-PF50 scores between three stature groups

\begin{tabular}{lccccc}
\hline & R-short & Average & R-tall & $F^{\text {a) }}$ & $P_{\text {-value }}$ \\
\hline General health perception score & $62.1 \pm 23.4$ & $64.0 \pm 20.3$ & $70.6 \pm 19.1$ & 4.774 & $0.009(1<3)^{b)}$ \\
\hline
\end{tabular}

Values are presented as mean \pm standard deviation.

CHQ-PF50, child-health questionnaire-parent form 50; R-short, relatively short children; R-tall, relatively tall children.

a) Analysis of variance. ${ }^{\text {b) }}$ Post hoc Scheffe test: 1, R-short; 2, Average; 3, R-tall.

Table 5. Parents expected height according to the stature groups

\begin{tabular}{lccccc}
\hline Sex & R-short & Average & R-tall & $F^{\text {b) }}$ & $P$-value \\
\hline Boys & $178.4 \pm 4.0$ & $179.9 \pm 2.8$ & $181.5 \pm 3.7$ & 10.729 & $<0.001(1<3)^{\text {b) }}$ \\
Girls & $163.0 \pm 3.9$ & $166.2 \pm 3.2$ & $168.0 \pm 2.9$ & 22.149 & $<0.001(1<2<3)^{\text {b) }}$ \\
\hline
\end{tabular}

Values are presented as mean \pm standard deviation.

R-short, relatively short children; R-tall, relatively tall children.

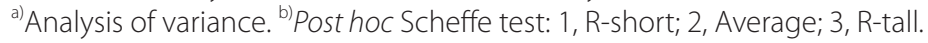

Table 6. Perception and help-seeking behaviors of parents for height improvement

\begin{tabular}{|c|c|c|c|c|c|}
\hline Variable & R-short $(n=30)$ & Average $(n=131)$ & R-tall $(n=153)$ & Chi-square $^{\text {a) }}$ & $P$-value \\
\hline Medicine $^{b)}$ & 11 & 36 & 25 & 8.33 & 0.016 \\
\hline Milk & 24 & 74 & 71 & 12.03 & 0.002 \\
\hline Early sleep & 25 & 97 & 102 & 4.21 & 0.122 \\
\hline Growth hormone & 8 & 20 & 18 & 4.52 & 0.104 \\
\hline Physical exercise & 25 & 95 & 98 & 5.40 & 0.067 \\
\hline GnRHa treatment & 4 & 6 & 12 & 3.19 & 0.203 \\
\hline None & 3 & 6 & 11 & 1.54 & 0.463 \\
\hline
\end{tabular}

Each number represents the respondents who each item helps to height improvement.

R-short, relatively short children; R-tall, relatively tall children; GnRHa, gonadotropin-releasing hormone agonist.

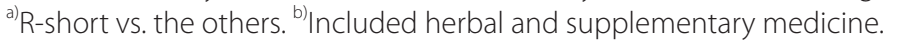


test $\left(X^{2}\right)=31.2520, P<0.001 ; X^{2}=15.600, P<0.001 ; X^{2}=7.470$, $P=0.024$, respectively) (Table 6).

\section{Discussion}

This study aimed to evaluate psychopathology, stress, and QoL based on the heights of children and their parents in a local community of a city in Korea. The results showed that children who were R-short considered themselves to be physically weaker than those who were of average height or tall; however, they did not show any differences in terms of psychopathology and stress.

Not many psychopathological studies have been conducted on short children in local communities; however, Voss et al. ${ }^{18-}$

${ }^{20)}$ conducted a prospect cohort study in 1989, and claimed that low-height children did not have any significant psychosocial issues. The follow-up studies reported that low-height children generally had slightly lower intelligence, but such a finding was more related to other social economic variables than the low height itself ${ }^{18-20)}$. In the present study, the R-short group and other groups did not have any significant differences in social economic factors, and we did not examine their intelligence or academic performance.

As illustrated in the first hypothesis of this study, previous studies reported that low-height children were more vulnerable to psychopathological issues such as anxiety, introversion, stigmatization, and juvenilization. However, those studies were conducted on children who were referred to a pediatric clinic or were given GH injections. Therefore, the results were different from present study $\mathrm{y}^{4,6,21-23)}$. The psychiatric tools used in this study include the K-CBCL, the BEPSI, and the CHQ-PF50.

Out of the indicators for problematic behavior syndrome in K-CBCL, 11 indicators such as withdrawn, somatic complaints, anxious/depressed, social problems, thought problems, attention problems, delinquent behavior, aggressive behavior, internalizing problems, externalizing problems, and total problems could be evaluated for the age group in the present study. The T scores of the 3 groups on 11 of these indicators were compared, and none of these items demonstrated significant differences. The parents' evaluation showed that obese children tended to have significantly higher scores for multiple items such as social problems, delinquent behavior, aggressive behavior, externalizing problems, total problematic behavior, etc., than did the overweight and normal-weight children. This suggests that issues with appearance and looks are more related to obesity or overweight, than with height. However, since the present study was conducted on children who were slightly short but who were still in the normal height range, the results could be different from what was expected.

We used the modified BEPSI ${ }^{17)}$ to evaluate the stress level. The K-BEPSI was developed by Yim et al. ${ }^{24)}$. The modified BEPSI has been proven to be valid and reliable. The present study examined children's stress level based on their parents' report. The total K-BEPSI score of the participants fell between 5 and 25 , the average score was 8.17, and the SD was 2.68 in this study. The three height groups did not exhibit any significant differences. Based on the K-BEPSI, 23 children who exhibited scores with SD that was 1.5 or higher were classified as the high stress group. The average height of the high stress group was $162.6 \mathrm{~cm}(\mathrm{SD}, 7.9 \mathrm{~cm})$, which was significantly higher than 154.1 $\mathrm{cm}(\mathrm{SD}, 16.2 \mathrm{~cm})$, the average height of the control group. Such a difference was still significant even when age was adjusted with covariates. Additionally, the difference between weight and BMI was not significant, but BMI of the high stress group tended to be lower. Age of high stress group was significantly higher than control. In summary, we could assume that children who were older age tended to struggle with stress more than others did. On the other hand, their BMI was actually lower, which indicated that they could not properly gain weight due to stress. But it is needed more information to analyze cause of stress in older age (Table 1). Further, the main mental health indexes in the high stress group were evaluated with the K-CBCL, and most of these indexes had lower values. Out of 15 indexes for value of QoL, which was evaluated with the CHQ-PF50, scores on 13 indexes were significantly lower. In other words, stress not only affected children's physical functions but also led to failure in performing expected roles. It also lowered their self-efficacy and mental health, and negatively affected family relationships. This indicates that stress lowers the overall QoL (Tables 2,3).

The CHQ-PF50 scores of the 3 groups based on height showed that most indicators did not have any significant differences, except for the general health perceptions. Parents with low-height children tended to consider their children to have health problems. The studies showed that these parents preferred providing their children with herbal medicine, growth supplements, and milk as help-seeking behaviors instead of providing them with medical treatment. This suggests that it is necessary to provide low-height children and their parents with accurate medical information. In one similar study, Kusalic et al. ${ }^{22)}$ reported that low-height children were considered physically weaker than their peers, which led their parents to overprotect them. Previous studies on body measures and the alternative remedies in Korea also showed that various types of alternative remedies were tried when children had lower height, weight, and BMI, but the expected height or the adult height was not significantly affected by how often the alternative remedies were used ${ }^{2}$.

A short stature, as an isolated physical characteristic, has been investigated as a predictor of an individual's psychological adaptation and QoL. However, it is difficult to conclude the same due to a variety of research models and each restriction. Since there is no evidence that children grow taller when alternative remedies are used, it is vital to help parents understand that short children do not necessarily have health issues, and that they do not need any special medical treatments for being short.

For this, it is necessary to develop and evaluate psychological counseling and cognitive-behavioral intervention programs to support the adaptation process of people with short stature. Additionally, it may not be possible to document evidence that GH treatment improves QoL. However, if the expectation for 
height is high and the consequent mental stress is severe, as an adjunct or alternative treatment to medical (endocrinological) treatment, growth-promoting therapies are necessary ${ }^{25)}$.

As a supplemental study, the parents' preferred adult height of their children was investigated. The standard growth curve published in 2007 demonstrated that the average height of almost fully-grown teenagers between the ages of 18 and 19 years was $173.4 \mathrm{~cm}$ for males and $160.7 \mathrm{~cm}$ for females ${ }^{13)}$. Parents with children who were R-short and who fell in the 25th percentile or lower in the present study wanted their kids to be taller than the average. Further, these parents' preferred height was $178.4 \mathrm{~cm}$ for sons and $163.0 \mathrm{~cm}$ for daughters. Additionally, the average height for parents was $172 \mathrm{~cm}$ for fathers and 159 $\mathrm{cm}$ for mothers, and the parents wanted their children to be at least $5 \mathrm{~cm}$ taller than the parents' average height. The taller the kids were currently, the taller the parents wanted them to be in the future. Other studies conducted on adolescents in Korea showed that the preferred average height of children according to parents was $178-180 \mathrm{~cm}$ for males and $165-168 \mathrm{~cm}$ for females, and this demonstrated that parents' expectations for their children's height was consistently high ${ }^{2,26)}$.

The present study was significant in that first, it was conducted on children and parents in the local community, while most of the previous studies were conducted on children who visited the clinic or patients with health problems. Secondly, it investigated the height recognition and stress level in R-short children instead of small children who are medically defined to be short because most children who visit growth clinics were in the 25th to 50th percentiles. Finally, the present study is different from others because it enhanced the research methods compared to those used in previous studies by using a variety of measurement methods such as the CBCL, BEPSI, and CHQPF50.

However, the results of the present study are limited because the number of children in the low-height group was relatively low, and all measurements were based on parents' report. Such limitations must be improved, and large-scale studies must be conducted in the future.

In conclusion, in the present study, children and their parents in local communities did not show any psychopathological or life value differences based on height. However, when children were short, their parents tended to regard short children as having health problems. Also, the parental expectation for their child's attainable height is unrealistically tall, mostly due to lack of correct medical information.

\section{Conflict of interest}

No potential conflict of interest relevant to this article was reported.

\section{References}

1. Kim JB, Yoo HW. Etiological classifications of children with chief complaint of short stature. J Korean Soc Pediatr
Endocrinol 1997;2:1-9.

2. Lee MC, Kim MJ, Choi IJ, Cheuh HW, Yoo JH. Complementary therapies and perceptions of growth in parents and children visiting the growth clinic. J Korean Soc Pediatr Endocrinol 2008;13:73-80.

3. Rudman D, Kutner MH, Blackston RD, Jansen RD, Patterson JH. Normal variant short stature: subclassification based on responses to exogenous human growth hormone. J Clin Endocrinol Metab 1979;49:92-9.

4. Gordon M, Crouthamel C, Post EM, Richman RA. Psychosocial aspects of constitutional short stature: social competence, behavior problems, self-esteem, and family functioning. J Pediatr 1982;101:477-80.

5. Money J, Pollitt E. Studies in the psychology of dwarfism. II. Personality maturation and response to growth hormone treatment in hypopituitary dwarfs. J Pediatr 1966;68:38190.

6. Stabler B, Clopper RR, Siegel PT, Stoppani C, Compton PG, Underwood LE. Academic achievement and psychological adjustment in short children. The National Cooperative Growth Study. J Dev Behav Pediatr 1994;15:1-6.

7. Kranzler JH, Rosenbloom AL, Proctor B, Diamond FB Jr, Watson M. Is short stature a handicap? A comparison of the psychosocial functioning of referred and nonreferred children with normal short stature and children with normal stature. J Pediatr 2000;136:96-102.

8. Lee JM, Appugliese D, Coleman SM, Kaciroti N, Corwyn RF, Bradley RH, et al. Short stature in a population-based cohort: social, emotional, and behavioral functioning. Pediatrics 2009;124:903-10.

9. Sandberg DE, Brook AE, Campos SP. Short stature: a psychosocial burden requiring growth hormone therapy? Pediatrics 1994;94(6 Pt 1):832-40.

10. Theunissen NC, Kamp GA, Koopman HM, Zwinderman KA, Vogels T, Wit JM. Quality of life and self-esteem in children treated for idiopathic short stature. J Pediatr 2002;140:507-15.

11. Sandberg DE. Quality of life and self-esteem in children treated for idiopathic short stature. J Pediatr 2003;143:691.

12. Whitman BY, Myers S, Carrel A, Allen D. The behavioral impact of growth hormone treatment for children and adolescents with Prader-Willi syndrome: a 2-year, controlled study. Pediatrics 2002;109:E35.

13. Moon JS, Lee SY, Nam CM, Choi JM, Choe BK, Seo JW, et al. 2007 Korean National Growth Charts: review of developmental process and an outlook. Korean J Pediatr 2008;51:1-25.

14. Achenbach TM. Manual for the child behavior checklist/418 and 1991 profile. Burlington (VT): Department of Psychiatry, University of Vermont, 1991.

15. Cho SC, Lee YS. Development of the Korean form of the Kovacs' Children's Depression Inventory. J Korean Neuropsychiatr Assoc 1990;29:943-56.

16. Landgraf JM, Abetz L, Ware JE. Child health questionnaire (CHQ): a user's manual. Boston (MA): Health Institute, 
New England Medical Center, 1996.

17. Frank SH, Zyzanski SJ. Stress in the clinical setting: the brief encounter psychosocial instrument. J Fam Pract 1988;26:533-9.

18. Downie AB, Mulligan J, Stratford RJ, Betts PR, Voss LD. Are short normal children at a disadvantage? The Wessex growth study. BMJ 1997;314:97-100.

19. Voss L, Walker J, Lunt H, Wilkin T, Betts P. The Wessex growth study: first report. Acta Paediatr Scand Suppl 1989;349:65-72.

20. Voss LD, Bailey BJ, Mulligan J, Wilkin TJ, Betts PR. Short stature and school performance: the Wessex Growth Study. Acta Paediatr Scand Suppl 1991;377:29-31.

21. Cuttler L, Silvers JB, Singh J, Marrero U, Finkelstein B, Tannin G, et al. Short stature and growth hormone therapy. A national study of physician recommendation patterns. JAMA 1996;276:531-7.
22. Kusalic M, Fortin C, Gauthier Y. Psychodynamic aspects of dwarfism: response to growth hormone treatment. Can Psychiatr Assoc J 1972;17:29-34.

23. Stabler B, Siegel PT, Clopper RR, Stoppani CE, Compton PG, Underwood LE. Behavior change after growth hormone treatment of children with short stature. J Pediatr 1998;133:366-73.

24. Yim JH, Bae JM, Choi SS, Kim SW, Hwang HS, Huh BY. The validity of modified Korean-translated BEPSI (Brief Encounter Psychosocial Instrument) as instrument of stress measurement in outpatient clinic. J Korean Acad Fam Med 1996;17:42-53.

25. Noeker M, Haverkamp F. Adjustment in conditions with short stature: a conceptual framework. J Pediatr Endocrinol Metab 2000;13:1585-94.

26. Lee WD, Lieu JW, Lee JW, Lee JS, Cho KL. A study on the attitudes of middle school students concerning height. Korean J Pediatr 2008;51:248-55. 